\title{
Semelhanças de família e generalização acerca das artes
}

\author{
Maurice Mandelbaum \\ INTRODUÇÃAO, TRADUÇÃO E NOTAS EUClides BarbosA
}

\section{Introdução}

Como propôs William E. Kennick no seu artigo de 1958 intitulado Does traditional aesthetics resides on a mistake? (A estética tradicional reside num erro?), (p. 32I) se experimentarmos pedir para que alguém entre num armazém cheio de todo tipo de coisas, sejam elas máquinas, ferramentas, barcos, igrejas, cadernos, pinturas, ventiladores ou partituras musicais, e que de lá ele retire tudo aquilo que ele considera ser uma obra de arte, diriamos (e essa é uma palavrachave) que ele muito provavelmente completará a tarefa com sucesso, ainda que essa mesma pessoa não consiga nos deixar claro o que ela entende por "obra de arte". Na verdade, nem mesmo os estudiosos da área de investigação filosófica chamada Estética alcançaram um consenso razoável sobre isso e essa tem sido uma preocupação desde os tempos antigos, com Platão e Aristóteles, passando por Santo Agostinho e Immanuel Kant, até os tempos atuais.

Em 1954, William Elton coletou uma série de artigos dos mais influentes pensadores da contemporaneidade sobre o assunto, como W. B. Gallie, Beryl Lake, Stuart Hampshire e Paull Ziff, ainda que os textos escolhidos não o tivessem sido de modo aleatório. A proposta de Elton, na publicação de um livro antológico

\footnotetext{
${ }^{\mathrm{I}}$ Doutorando no departamento de filosofia da UFRN.
} 
chamado Aesthetics and language [Estética e linguagem] era mostrar a tendência atual de passar a tentar a explicar os fenômenos e conceitos da estética tradicional com base em métodos de investigação da filosofia da linguagem, a qual recebia grande ênfase na filosofia.

Tendo início com os relevantes trabalhos de Gottlob Frege (Os fundamentos da aritmética, I884) e Bertrand Russell (Da denotação, 1905), esse boom se deu principalmente após a publicação póstuma do filósofo alemão Ludwig Wittgenstein (I889-1951) e suas Investigaçôes filosóficas (1953), com a qual surpreendeu o mundo quando nos atentou a algo que parecia óbvio, mas que não teve grande atenção até então: que os significados dos termos linguísticos são relativos ao contexto da enunciação, aos diversos fatores presentes durante seu uso, 2] não como se pensava desde Platão, isto é, que a cada termo deveria existir um objeto ideal fixo ao qual corresponde metafisicamente.

Wittgenstein estava dando origem ao que hoje chamamos de pragmática linguistica, que é o ramo da filosofia e da linguística no qual estudamos como os significados são alterados de acordo com a situação na qual ocorrem. Ela foi criada, inclusive, sob certo pré-conceito de ser considerada como pouco rigorosa, por exemplo, em relação à lógica clássica, justamente por considerar toda essa mutabilidade da linguagem (mais sobre a informalidade e o problema de definição da pragmática). 3. Por exemplo, sabemos que "amanhã irei na sua casa” pode ter vários significados a depender do dia em que foi enunciado, uma vez que o dêitico "amanhã" (Ibid., p. 65) é relativo aos outros "hoje” ou “ontem”. Sabemos também que "poderia passar o sal?" não se trata de uma pergunta acerca das capacidades do interlocutor de mover o sal até o locutor, mas de um pedido de que, por favor, o faça. Neste último caso, temos um exemplo de um ato de discurso indireto: ${ }_{4}^{4}$ cuja teoria desenvolvida por John Searle e Daniel Vanderveken no Foundations of illocutionary logic (1985) teve origem com John Langshaw Austin no seu póstumo How to do things with words (Como fazer coisas com palavras, 1962), resultado de

${ }^{2}$ WITTGENSTEIN, L. Investigaçôes filosóficas. Trad. José Carlos Bruni, 3. ed. São Paulo: Abril Cultural, 1984 (1953), $\$ 43$, p. 28.

${ }^{3}$ Cf. LEVINSON, S. C. Pragmática. Trad. Aníbal Mari e Luiz Carlos Borges. I. ed. São Paulo: Martins Fontes - WMF, 2007, p. 6.

${ }^{4}$ SEARLE, J. R.; VANDERVEKEN, D. Foundations of illocutionary logic. Nova York: Cambridge University Press, 1985, p. 25. 
uma transcrição de palestras feita por seus estudantes em 1955. Nesta obra, vimos que uma enunciação de uma sentença performativa (p. 6) do tipo "eu nomeio este navio como Rainha Elizabeth" não se trata de uma mera descrição, relato ou afirmação da ação de nomear, mas é o fazer do nomear, propriamente.

Orbitando todo esse contexto (passado e futuro), a proposta de Elton era mostrar, com o auxílio dos artigos que apresentaria em sua coleção, que muitas das confusóes presentes nas teorias estéticas advinham de problemas fundamentalmente linguísticos. As novas estratégias de análise vinham principalmente das faculdades inglesas (Oxford, Cambridge e Londres), mas também havia contribuições dos Estados Unidos. A principal motivação para isso se devia ao fato de que o estudo da estética estava fadado à obscuridade e "pura verborragia". 5 demonstrando uma ironia na qual, justamente na área da filosofia que trata da criatividade e da "iluminação", era ela a "ciência pesadelo", maçante, opaca, falsa e estéril. Elton, mencionando C.I. Lewis: "em toda a área de estudos filosóficos não há provavelmente outro tópico que seja marcado por tanta obscuridade e tão pouca unanimidade como é exibido o tema da teoria estética" 6

A acusação de que a linguagem estava sendo mal-usada para fins outros que não fossem a compreensão clara e direta do que estava sendo dito já havia sido feita alguns anos antes por George Orwell em seu artigo Politics and english language (1946), na qual ele chegou a criar termos como "o bom inglês" e o "inglês moderno". O primeiro tem a intenção tradicional de informar o máximo possível o interlocutor no menor intervalo de tempo, enquanto o último esquece completamente essa tarefa, almejando apenas a vitória no debate (no caso, político) e a confusão das ideias da audiência. No primeiro parágrafo, ele diz que: "abaixo de tudo isso reside uma crença semiconsciente de que a linguagem é um crescimento natural e não um instrumento o qual moldamos para o nosso próprio interesse", 7 Posteriormente, Paul Grice no seu Logic and conversation (Lógica e conversação,

5 "sheer verbiage" (ELTON, William. Aesthetics and language. Basil Blackwell Oxford, 1959 (1954), p. 2).

6 "in the whole area of philosophic studies there is probably no other topic which is marked by so much unclarity and so little unanimity as is exhibited by the subject of esthetic theory" (Id. Ibid.).

7 "Underneath this lies the half-conscious belief that language is a natural growth and not an instrument which we shape for our own purposes" (sem paginação). 
1967) também já notou que os seres humanos que se propóem a uma interação linguística racional procuram sempre "observar" (isto é, pressupor) um princípio cooperativo ${ }^{8}$ o qual nos orienta a: "faça sua contribuição conversacional do modo como é requerida, no estágio em que ocorre, através do propósito ou direção aceitos na troca conversacional em que você está inserido".

Tudo isso tornou óbvio que a tradição da filosofia analítica precisava tomar a frente para tentar ao menos tornar mais frutífera a área da estética, deixando de lado ao máximo possível toda e qualquer ambiguidade e falta de clareza. Era necessária uma análise lógico-semântica dos termos utilizados e a influência que causara Wittgenstein com suas Investigaçôes na mudança do que compreendíamos por "significado" foi o ponto-chave para o início dessa revolução. Mas, afinal, como seria essa nova abordagem?

Elton começa destacando que do fato de nos referirmos a "arte" ou "estética" com apenas um substantivo, não podemos disso simplesmente concluir que somos capazes de encontrar uma "essência" presente em todos os objetos referidos como tal e, assim, realizarmos generalizaçóes. Essa tendência se revela a partir da clássica crença platônica de que só compreendemos algo se conhecermos suas origens, isto é, suas propriedades definitórias e ideias. Segundo o autor, às vezes acabamos por confundir categorias por propriedades, de modo que as primeiras nos orientam apenas, no contexto de investigação, a que tipo de perguntas devemos fazer, enquanto as segundas nos comprometem a atribuir qualidades a objetos as quais muitas vezes podem estar equivocadas.

$\mathrm{O}$ autor comenta também que parte dessa obscuridade vem da tentativa de alguns autores em realizar analogias inapropriadas com ramos da filosofia já conhecidos, como a ética. É no mínimo curioso considerarmos que uma obra de arte possa ser "boa", "única", "gratuita" ou mesmo "pobre".

Elton, mencionando os argumentos dos diversos autores de sua antologia, nos diz que é uma tendência, em decorrências dos fatos destacados anteriormente, que frases como "arte é expressão" ou "arte é forma significante" acabem sendo

${ }^{8}$ GRICE, H. P. Logic and conversation. William James Lectures, delivered at Harvard University in 1967 , and to be published by Harvard University Press. Copyright 1975 by II. Paul Grice, p. 43.

9 "Make your conversational contribution such as is required, at the stage at which it occurs, by the accepted purpose or direction of the talk exchange in which you are engaged.” 
excludentes devido à força de suas formas categóricas de expressão, influenciando o interlocutor a pensar que o problema da definição de arte se resume a tão simplesmente como fora dito. Outros ramos da filosofia, mais cautelosos e mais frutíferos, supostamente evitam esse tipo de discurso.

É óbvio que, se termos linguísticos são aplicados à formação das ferramentas de qualquer ciência, problemas antigos como os de ambiguidade certamente fundamentam muitas das confusóes encontradas na estética. Elton destaca que termos caros como "sentimento", "emoção" e "expressão", frequentemente utilizados no contexto da estética, sofrem muito desse problema. Por exemplo, é comum crer que quando alguém diz que "sinto que algo ruim está para ocorrer", automaticamente ele possui o estado mental do medo ou expectativa. Talvez esse sentimento não signifique qualquer coisa para ele. Será que esse algo "ruim" é "realmente" ou unanimemente considerado prejudicial ao locutor, mesmo ele sendo sincero? (Neste caso, a conotação de "ruim” está relativa ao contexto). Será que necessariamente ele precisa tomar uma atitude quanto a isso? O autor nos diz que é normal que o teórico acabe por "deduzir" que um pintor, enquanto trabalha, esteja obrigatoriamente querendo expressar alguma emoção que ele deve estar sentindo naquele momento e que a audiência deve se preparar para tentar compreendê-la, se ela leva a arte a sério, o que não parece correto (o artista pode estar sentindo algo ou tendo uma emoção completamente distinta do que acham). É a partir disso que surgem perguntas como "o que essa pintura quer dizer?" ou asserçóes como "que música triste”, quando, na verdade, segundo o autor, há uma lacuna explanatória e uma não necessidade lógica entre o que algo é e o que algo expressa.

Seguindo os conselhos de Wittgenstein, o autor sugere que o melhor caminho para compreender o significado de um termo seria se perguntar, num contexto onde o termo é efetivamente aplicado, no caso da música, "como seria se a música fosse capaz de expressar tristeza?”, podendo concluir, por exemplo, que a tristeza não é algo de separável da música, mas estaria nela mesma, como a vida está em nós ou um personagem está no ator que o representa. Sobre isso, Deryck Cook lançava o seu The language of music (A linguagem da música, 1959), no qual ele tenta argumentar, com base em teoria musical, que alguns dados compositores tentaram expressar o mesmo sentimento a partir dos mesmos padróes de partituras e os sons 
que eles representam ao serem executados, criando uma espécie de "dicionário" musical bastante preliminar.

Debates em linguagem também dão origens a debates em ontologia, e o problema da existência da obra de arte e o que ela realmente é entra em pauta. Seria ela material ou imaginativa? Se por um lado tentamos deduzir um modelo ideal para qualquer uma delas, o que de fato nos afeta, e é comumente dito como a "obra de arte em si”, é sua instanciação material (afinal, "estética” vem do grego "aesthesis", que significa algo como a faculdade ou a capacidade de sentir). De fato, é notável que aspectos materiais não só alteram o resultado "final” da obra (supondo sua imutabilidade), como também dita tendências e novas maneiras de produzir arte. Por exemplo, o Coliseu se tornou hoje, depois de todos os efeitos do tempo, uma obra arquitetônica muito mais digna de ser chamada de "monumento" que na época em que era efetivamente utilizado para as batalhas de gladiadores. Também, alguns acidentes de misturas de tintas deram origem a "novas" cores que viriam a ser utilizadas por artistas posteriores. Se a obra de arte é subjetiva e sua forma material é apenas um ponto de iniciação da "real obra", ainda é tema de grande discussão. Será que a música que toca no disco é a mesma da que foi tocada pela banda ao vivo? O que conta para a sua identidade? Seu nome, a maneira como soa, ou apenas a composição construída a partir da teoria musical? A música é a sua primeira ocorrência no mundo ou o conjunto de todas as performances possíveis dela? Há aquilo que seja realmente a música?

Talvez, destaca Elton, o problema não fosse sobre a existência (ou como ela se dá) dos objetos que são as obras de arte, uma vez que jamais teríamos acesso ao conteúdo mental presente na mente do artista, mas a real questão estaria na interpretação delas a partir de cada um da audiência e que no conjunto de todas as interpretações, como quando pessoas falam sobre uma obra de arte, é que ela tomaria sua forma mais relevante. Mais uma vez, como orientou Wittgenstein, o significado de obra de arte teria a ver com o contexto onde aparece e das palavras e expressóes utilizadas para se referir a ela.

A questão, como vemos, está no significado dos termos. "Uma boa obra de arte”, dita por alguém, o compromete a gostar dela ou mesmo recomendá-la? Provavelmente não. Ainda, que critérios são utilizados para a classificação de bom ou ruim? Certamente depende de quem, onde e quando se fala, a que propósitos 
tal julgamento irá interessar etc. Se obras de arte são únicas, poder-se-ia até dizer que elas são incomparáveis entre si.

Qualquer analogia com a ciência seria descabida, uma vez que os dados científicos costumam independer do dia e local em que foram coletados, enquanto obras de arte são reinterpretadas constantemente. Também parece pouco plausível dizer que um poema foi "substituído" por outro, como ocorre entre teorias científicas. Poderíamos até substituir alguma teoria subjacente a uma crítica estética, mas nunca uma obra de arte por outra. Por último, com base nessa aparente falta de possibilidade de moldar critérios de julgamento, ninguém pode ser "provado errado" por gostar de uma determinada obra de arte.

Como diz Elton: "Arte sendo criação, mais do que descoberta, critica e avaliação lembram mais criação do que demonstração ou prova”, I0 mas disso não precisamos nos conter em criar sistemas de avaliação com relação a certos critérios (por exemplo, cada festival de prêmios de cinema tem seus próprios critérios). Assim, sobre um crítico de arte, "o veredito que ele enuncia não nomeia uma qualidade simples, nem um simples sentimento na critica. 'isso ébom' também tem a forma do veredito impessoal 'ele é culpado"' "⿴囗十 $\mathrm{A}$ tarefa do crítico não seria a de tentar explicar experiências estéticas, como faria um cientista, mas de "clarificálas" (isto é, apresentá-las sob algum contexto) ou (consequentemente) alterá-las. Vale destacar o uso do verbo "lembrar" na primeira citação deste parágrafo e sua alusão ao conceito de Semelhanças de familia ${ }^{12}$ com o qual ele expressa que entre a criação e a descoberta há certamente semelhanças, mas cada uma pertence a um Jogo de linguagem ${ }^{\text {五 }}$ específico.

É claro que o filósofo anseia por uma teoria geral e sucumbir ao relativismo subjetivo não é uma conclusão desejada (é o que já tínhamos desde o começo),

Io Tradução do autor de: "Art being creation, rather than Discovery, criticism and appraisal resemble more creation than demonstration, or proof”. (ELTON, William. Aesthetics and Language. Basil Blackwell Oxford, 1959 (1954), p. ro.)

II Tradução do autor de: "The veredict he delivers does not name a simple quality, nor a simple feeling in the critic; 'this is good' also has the form of the impersonal veredicto, 'he is guilty"” (Id. Ibid.)

${ }^{12}$ WITTGENSTEIN, L. Investigaçôes filosóficas. Trad. José Carlos Bruni, 3. ed. São Paulo: Abril Cultural, 1984 (1953), $\$ 67$ p. 39.

${ }^{13}$ Id., $\$ 7$, p. I2. 
mas forçar analogias com a ciência ou outros ramos da filosofia podem acarretar problemas ainda maiores.

A presente tradução inglês-português do texto Family resemblances and generalizations concerning the art $5^{\sqrt{14}}$ de Maurice Mandelbaum publicado em 1965 trata de algumas críticas feitas por Mandelbaum a tais aplicações de estratégias da filosofia analítica britânica na elucidação de conceitos estéticos, mas principalmente à aplicação do conceito de semelhanças de família de Wittgenstein.

\section{Referências}

AUSTIN, John L. How to do things with words. The William James Lectures, delivered at Havard University in 1955. Oxford: Oxford Clarendon Press, 1962. COOKE, Deryck. The language of music. Nova York: Oxford University Press, 200I (1959).

ELTON, William. Aesthetics and language. Basil Blackwell Oxford, 1959 (1954). GRICE, Herbert Paul. Logic and conversation. William James Lectures, delivered at Harvard University in 1967 , and to be published by Harvard University Press. Copyright 1975 by II. Paul Grice.

KENNICK, William E. “Does traditional aesthetics rest on a mistake?” In: Mind, New Series, v. 67, n. 267, pp 317-334. Oxford University Press, 1958.

LEVINSON, Stephen C. Pragmática. Trad. Aníbal Mari e Luiz Carlos Borges. I. ed. São Paulo: Martins Fontes - WMF, 2007.

MANDELBAUM, Maurice. "Family resemblances and generalizations concerning the arts”. In: American Philosophy Quarterly, v. 2, n. 3, pp. 219-228. University of Illinois Press, 1965.

ORWELL, George. "Politics and the english language". Horizon. Londres, 1946. Disponível em: $<$ http://www.orwell.ru/library/essays/politics/ english/e_polit >. Acesso em: 23 nov. 202I.

SEARLE, John. R.; VANDERVEKEN, Daniel. Foundations of illocutionary logic. Nova York: Cambridge University Press, 1985.

${ }^{14}$ Gostaria de agradecer profundamente os direitos de tradução cedidos gentilmente por Nicholas Rescher, editor executivo da American Philosopby Quarterly. Muito Obrigado. 
WITTGENSTEIN, Ludwig. Investigaçôes filosóficas. Trad. José Carlos Bruni, 3. ed. São Paulo: Abril Cultural, 1984 (1953).

\section{Semelhanças de família e generalização acerca das artes}

Em 1954 William Elton coletou e publicou um grupo de ensaios sob o título Estética e linguagem. Assim como sua introdução tornou claro, uma propriedade comum desses ensaios foi a aplicação a problemas estéticos de algumas doutrinas características da recente filosofia linguística britânica ${ }^{\text {I5 }}$. Enquanto esse modo de filosofar não teve uma influência tão pervasiva em estética como teve em outros ramos da filosofia ${ }^{16}$ houve um número de importantes artigos os quais, em adição àqueles contidos no volume de Elton, sugerem a direção na qual essa influência tem efeito. Dentre esses artigos pode-se mencionar "A tarefa da definição de uma obra de arte” por Paul Ziff: ${ }^{17}$ “"O papel da teoria em estética” por Morris Weitz: ${ }^{18}$ "Sobre 'o que é um poema" reside num erro?" ${ }^{20}$ de W. E. Kennick. Em cada um deles se pode achar uma convicção a qual estava também presente na maioria dos ensaios no volume de Elton: de que é um erro oferecer generalizaçóes acerca das artes, ou, colocando o assunto de uma maneira mais provocativa, de que é um erro tentar discutir o que arte, ou o belo, ou a estética, ou um poema, essencialmente é. Em suporte

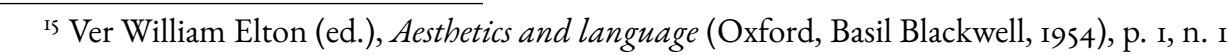
e 2 .

${ }^{16}$ Uma discussão desse fato é encontrada no artigo de Jerome Stolnitz, "Notes on analytic philosophy and aesthetics", British Journal of Aesthetics, v. 3 (196I), pp. 210-222.

${ }^{17}$ Philosophical Review, v. 62 (1953), pp. 58-78.

${ }^{18}$ Journal of Aesthetics and Art Criticism, v. I5 (1956), pp. 27-35.

${ }_{19}$ Philosophical Review, v. 66 (1957), pp. 329-362.

${ }^{20}$ Mind, v. 67 (1958), pp. 317-334. Em adição aos artigos já referidos, posso mencionar "The uses of works of arts” por Teddy Brunius noJournal of Aesthetics and Art Criticism, v. 22 (1963), pp. I23-I33, o qual menciona tanto Weitz como Kennick, mas levanta outras questóes sobre as quais não estou tratando aqui. 
parcial a essa argumentação, alguns autores fizeram uso explícito da doutrina de Wittgenstein de semelhanças de familia; Morris Weitz, por exemplo, a colocou na linha de frente de sua discussão. Entretanto, naquele influente e frequentemente antologizado artigo, o professor Weitz não fez qualquer tentativa de analisar, clarificar ou defender a doutrina nela mesma. Já que seu uso com respeito a estética proveu os meios pelos quais outros procuraram escapar da necessidade de generalização acerca das artes, eu devo começar minha discussão com uma consideração disso.

\section{I}

O locus classicus ${ }^{21}$ para a doutrina de Wittgenstein de semelhanças de família está na Parte I das Investigaçôes filosóficas, seçôes 65-77. ${ }^{22}$ Ao discutir aquilo a que ele se refere como jogos de linguagem, Wittgenstein diz:

Ao invés de produzir algo comum a tudo aquilo a que chamamos de linguagem, eu estou dizendo que esses fenômenos não têm uma coisa em comum a qual nos faz usar a mesma palavra para todas - mas elas estão relacionadas umas às outras de várias maneiras diferentes. E é por causa dessa relação, ou dessas relaçôes, que as chamamos todas de "linguagem". (\$65)

Ele então ilustra sua argumentação ao citar uma variedade de jogos, como jogos de tabuleiro, jogos de cartas, jogos de bola etc., e conclui:

Vemos uma complicada rede de relaçóes de similaridade se sobrepondo e se cruzando: às vezes similaridades gerais e de detalhe. (\$66)

Não posso pensar em expressão melhor para caracterizar essas similaridades do que "semelhanças de família"; porque as várias semelhanças entre membros de uma família: porte, características, cor

${ }^{21}$ Significa: a parte mais famosa ou influente. (N. da T.)

${ }^{22}$ Ludwig Wittgenstein, Philosophical investigations, traduzido por G. E. M. Anscombe (New York, Macmillan, 1953), pp. 3I-36. Uma passagem paralela é encontrada em "The blue rock": ver Preliminary studies for the Philosophical investigations, generally known as The blue and brown books (Oxford, Basil Blackwell, 1958), pp. 17-18. 
dos olhos, jeito de andar, temperamento etc. etc., se sobrepóem e se cruzam da mesma maneira. - E eu devo dizer: "jogos" forma uma família. $(\$ 67)$

Em suma, o que Wittgenstein pretende estabelecer é que não se deve supor que todas as instanciaçóes daquelas entidades sobre as quais aplicamos um nome comum de fato possuem alguma característica em comum. Ao invés disso, o uso de um nome comum é baseado no cruzamento e sobreposição de características semelhantes dentre outros objetos e atividades heterogêneos.

As ilustrações concretas de Wittgenstein sobre a diversidade dentre os vários tipos de jogos podem a princípio fazer sua doutrina de semelhanças de família extremamente plausível. Por exemplo, não hesitamos em caracterizar tênis, xadrez, bridg $\AA^{23}$ e paciência como jogos, mesmo que uma comparação entre eles falhe em revelar alguma característica específica a qual é a mesma em cada um deles. Não obstante, eu não acredito que a doutrina dele de semelhanças de família, tal como está, provê uma análise adequada do porquê um nome comum, como em "um jogo", é em todos os casos aplicado ou mantido.

Considere primeiro o seguinte caso. Vamos assumir que você saiba como jogar aquela forma de paciência chamada "Canfield" " ${ }^{24}$ suponha também que você está familiarizado com um número de outras variedades de paciência (Wittgenstein usa "paciência”, ou seja, "solitaire", como uma instância de uma forma de jogo). ${ }^{25}$ Estando você a me ver embaralhando um conjunto de cartas, amontoando as cartas em pilhas, algumas com a face para cima e outras com a face para baixo, virando as cartas uma por uma, às vezes pondo-as em uma pilha, depois noutra, trocando as pilhas, etc. você pode dizer: "estou vendo que você está jogando cartas. Que jogo você está jogando?” Porém, a isso eu posso responder: “eu não estou jogando um jogo; estou contando (ou lendo) sortes". As semelhanças entre o que você me viu fazer e as características de jogos de cartas com os quais

${ }^{23}$ Contract Bridge (Ponte de contrato) ou simplesmente bridge (ponte) é um jogo para quatro pessoas divididas em dupla que utiliza um baralho padrão de 52 cartas. (N. da T.)

${ }^{24}$ Modo de jogo original e mais desafiador, no qual era necessário virar três e não apenas uma carta por tentativa. (N. da T.)

${ }^{25}$ Apesar de no Brasil chamarmos "solitaire" de "paciência”, na verdade são dois tipos de jogos com algumas sutis diferenças. (N. da T.) 
você é familiar permitirão você me contradizer e dizer que eu estou realmente jogando um tipo de jogo? Uso ordinário ou não, creio eu, sancionando nossa descrição de leitura de sorte como um exemplo de jogar um jogo, não importa quão impactante possam ser as semelhanças entre as formas com as quais cartas são manuseadas ao jogar paciência e em ler sortes. Ou, para escolher outro exemplo, podemos dizer que enquanto certas formas de campeonatos de luta livre são às vezes caracterizadas como jogos “(Wittgenstein menciona "Kampfspiele") ${ }_{2}^{26}$ uma luta raivosa entre dois rapazes, cada um tentando fazer o outro se render, não é para ser caracterizado como um jogo. Ainda que se possa encontrar uma grande quantidade de características semelhantes entre tal luta e uma partida de luta livre num ginásio. $\mathrm{O}$ que parece ser crucial em nossa designação de uma atividade como um jogo é, portanto, não meramente uma questão de notar um número de semelhanças específicas entre ele e outras atividades as quais denotamos como jogos, mas envolve algo a mais.

Para sugerir que tipo de característica esse "algo a mais" possivelmente é, será conveniente prestar mais atenção à noção do que constitui uma semelhança de família. Suponha que te mostrem dez ou uma dúzia de fotografias e então você é solicitado a decidir quais dentre elas exibem semelhanças fortes ${ }^{27}$ Você pode não ter dificuldade em selecionar, digamos, três das fotografias nas quais os indivíduos possuem marcadamente cabeças arredondas, um perfil fortemente prógnato, notáveis olhos profundos e encaracolados cabelos escuros.$^{28}$ Em certa

${ }^{26}$ Ludwig Wittgenstein, Philosophical investigations, \$66, p. 31. Por razôes obscuras, a senhorita Anscombe traduz "Kampfspiele" como "Jogos Olímpicos".

${ }^{27} \mathrm{Num}$ artigo que é intimamente relacionado às minhas discussões, mas usa diferentes argumentos para defender um objetivo similar, Haig Khatchadourian mostrou que Wittgenstein é menos explícito do que ele deveria ter sido com respeito aos níveis de determinabilidade pelos quais essas semelhanças são significantes para nosso uso de nomes comuns. Ver "Common names and 'family resemblances", Philosophy and Phenomenological Research, v. I8 (1957-58), pp. 34I-358. (Para um artigo relacionado, mas menos intimamente relevante do Professor Khatchadourian, ver "Art-names and aesthetic judgments", Philosophy, v. 36 [I96I], pp. 30-48).

${ }^{28}$ Pode ser notado que isso constitui uma semelhança mais próxima do que aquela envolvida no que Wittgenstein chama de "semelhanças de família", uma vez que na minha ilustração todas as similaridades específicas pertencem a um único conjunto de características, com respeito a cada um de todos os três sujeitos que diretamente lembram uns aos outros. No uso da noção de semelhanças de família de Wittgenstein há, entretanto, nenhum conjunto de características 
medida, você pode dizer num sentido metafórico que as similaridades dessas características constituem uma semelhança de família dentre eles. Esse sentido, porém, seria metafórico, uma vez que na falta de um parentesco biológico de um certo degrau de proximidade estaríamos inclinados a falar apenas em semelhanças e não em semelhanças de familia. O que marca a diferença entre um sentido literal e metafórico da noção de "semelhanças de família" é, portanto, a existência de uma conexão genética no primeiro caso e não no último. Wittgenstein, porém, falhou em tornar explícito o fato de que a noção raiz e literal de uma semelhança de família inclui essa conexão genética não menos do que inclui a existência de notável semelhança fisionômica ${ }^{29}$ Tivesse a existência de tal critério ambíguo sido tornada explícita por ele, o mesmo teria notado que há de fato um atributo comum a todos aqueles que possuem uma semelhança de família uns com os outros: eles estão relacionados por uma ancestralidade comum. Uma relação deste tipo não é, claro, uma dentre as características específicas daqueles que compartilham

comuns semelhantes para cada membro da "família"; há meramente uma sobreposição e cruzamento dentre os elementos os quais constituem as semelhanças dentre várias pessoas. Portanto, de modo a se adequar a seu uso, minha ilustração teria que ser feita de forma mais complicada e o nível de semelhança se tornaria mais atenuado. Por exemplo, teríamos que introduzir as fotografias de outros sujeitos nas quais, por exemplo, queixos recessivos substituiriam perfis prógnatos dentre aqueles que compartilharam as outras características; alguns teriam o cabelo loiro ao invés de escuro, e olhos protuberantes ao invés de profundos, mas em cada caso iriam se assemelhar aos outros em outros aspectos etc. Todavia, se o que eu disse acerca de semelhanças de família se sustenta nas fortes similaridades presentes na minha ilustração, deveria sustentar uma fortiori (versão mais forte) da forma de semelhanças de família mais fraca a qual Wittgenstein nos chama atenção.

${ }^{29}$ Ainda que Wittgenstein tenha falhado em tornar explícito o fato de que uma conexão genética estava envolvida em sua noção de "semelhanças de família”, eu creio que ele de fato pressupõe tal conexão. Se eu não estiver errado, o original em alemão mostra isso mais claramente do que a tradução de Anscombe. O texto alemão se lê: (conferir original no artigo de Mandelbaum). Modificando a tradução da senhorita Anscombe em alguns aspectos tanto quanto possível, eu sugiro que a tradução dessa passagem possa ser lida como: Não posso pensar em melhor expressão para caracterizar essas similaridades do que "semelhanças de família", uma vez que várias similaridades as quais são obtidas dentre os membros de uma família - suas formas, características, cor dos olhos, jeito de andar, temperamento, etc., etc. - se sobrepõem e se cruzam da mesma maneira.Essa tradução difere daquela da senhorita Anscombe (a qual foi citada acima) no fato de que torna mais explícito o fato de que as similaridades são similaridades dentre os membros de uma única família e não são elas mesmas definitivas ao que constitui uma semelhança de família. 
uma semelhança de família; ela não obstante os diferencia daqueles que não são referidos como membros de uma única família ${ }^{30}$ Se, então, é possível que a analogia de semelhança de família pudesse nos dizer algo sobre como jogos podem estar relacionados uns com os outros, se poderia explorar a possibilidade de que, apesar de suas grandes dissimilaridades, jogos podem possuir um atributo comum o qual, como conexão biológica, não é ele mesmo um dentre suas características diretamente exibidas. Infelizmente, essa possibilidade não foi explorada por Wittgenstein.

Para ter certeza, Wittgenstein não afirma explicitamente que as semelhanças as quais estão correlacionadas com nosso uso de nomes comuns devem ser de um tipo que é diretamente exibido. Não obstante, todas as suas ilustrações nas passagens relevantes envolvem aspectos de jogos os quais seriam incluídos numa descrição de como um jogo em particular deve ser jogado; isto é, quando ele nos comanda a "procurar e ver" se há algo comum a todos os jogos. $3^{13} \mathrm{o}$ "algo" é tomado a representar precisamente o tipo de característica manifesta que é descrita em manuais de regras, como em Hoyle. $3^{23}$ Todavia, como vimos no caso de semelhanças de família, o que constitui uma familia não é definido em termos de características manifestas de um grupo aleatório de pessoas; devemos primeiro caracterizar a relação familiar em termos de laços genéticos, e então observar em que medida aqueles que estão conectados dessa maneira se assemelham entre si 33

${ }^{30}$ Fosse esse aspecto do critério ambíguo abandonado, e fosse nosso uso de nomes comuns unicamente determinados pela existência de relações que se sobrepõem e se cruzam, seria difícil de ver como um consenso seria um dia estabelecido para difundir tais nomes. Robert J. Richman chamou atenção para o mesmo problema em "Something Common", Journal of Philosophy, v. 59 (1962), oo. 82I-830. Ele fala do que ele chama de "o Problema das Texturas Bem Abertas" e diz: "a noção de semelhanças de família pode abordar nossa extensão da aplicação de um dado termo geral, mas não parece estabelecer limite algum nesse processo” (p. 829). Num artigo intitulado "The Problem of Model-Language Game in Wittgenstein's Later Philosophy”, Philosophy, v. 36 (196I), pp. 333-35I, Helen Harvey também chama atenção ao fato de que "uma família é assim chamada em virtude de suas ancestralidades comuns” (p. 334). Ela também menciona (p. 335) o que Richman referiu como o problema da "textura bem aberta".

${ }^{3 \mathrm{I}}$ Ludwig Wittgenstein, Philosophical Investigations, \$66, p. $3 \mathrm{I}$.

${ }^{32}$ Uma enciclopédia de regras de jogos de estádio, mas principalmente de jogos de cartas. (N. da T.)

${ }^{33}$ Ainda que eu só tenha mencionado a existência de conexões genéticas dentre membros 
No caso de jogos, a analogia de laços genéticos pode ter o propósito a favor do qual vários jogos foram formulados por aqueles que os inventaram ou os modificaram, por exemplo, a potencialidade de um jogo que consiste em absorver interesse não prático tanto aos participantes quanto aos espectadores. Se existisse alguma característica comum não se poderia esperar que ela fosse definida num manual de regras, como no Hoyle, uma vez que manuais de regras apenas tentam nos dizer como jogar um jogo em particular: nosso interesse em jogar um jogo, e nossa compreensão do que constitui um jogo, já está pressuposto pelos autores desses livros.

Não é minha preocupação agora determinar alguma característica comum para a maioria ou a todas as atividades as quais chamamos de jogos, nem eu gostaria de discutir a analogia de semelhanças de família de que deve haver alguma característica dessas. Se a questão é para ser decidida, deve ser decidida por uma tentativa de "procurar e ver". Entretanto, é importante que procuremos no lugar certo e das maneiras certas se estamos procurando por uma característica comum; não devemos assumir que alguma característica comum a todos os jogos deve ser alguma característica manifesta, tal como se eles devem ser jogados com uma bola ou com cartas ou quantos jogadores devem existir para que o jogo possa ser jogado. Se tivéssemos que depender exclusivamente dessas características deveríamos, como eu sugeri, estar aptos a ligar paciência com leitura de sorte e partidas de luta livre com brigas, mais do que (digamos) ligar paciência com cribbagg $3^{34}$ e partidas de luta livre com levantamento de peso. Isto é, então, minha argumentação de que a ênfase de Wittgenstein nas semelhanças exibidas diretamente, e sua falha em considerar outras possíveis similaridades, leva a uma falha em sua contribuição em prover uma pista adequada ao que - em alguns casos, pelo menos - governa nosso uso de nomes comuns 35

de uma família, eu não deveria obviamente excluir os efeitos das associações habituais que dão origem a algumas das semelhanças as quais Wittgenstein menciona. Eu insisti em conexões genéticas apenas porque é a mais simples e mais óbvia ilustração do discurso que eu desejei realizar.

34 Trata-se de um jogo de cartas feito tradicionalmente para dois jogares, ainda que seja mais comum com três ou mais, cujo objetivo é agrupar certas combinaçôes de cartas. (N. da T.)

${ }^{35}$ Eu não nego que semelhanças diretamente exibidas frequentemente realizam uma contribuição em nosso uso de nomes comuns: isso é um fato explicitamente notado pelo menos desde Locke. Porém, similaridades em origem, similaridades em uso e similaridades em intenção po- 
Se as considerações anteriores estiverem corretas, estamos agora em posição de ver que a difamação radical de generalização acerca das artes, a qual veio a ser quase uma marca registrada dos escritos daqueles mais influenciados pela recente filosofia britânica, pode envolver sérios erros, e pode não constituir um avanço notável.

\section{II}

Partindo das afirmações de Wittgenstein acerca de semelhanças de família ao uso para o qual sua doutrina tem sido posta por escritos em estética, devemos primeiro notar o que esses autores não estão tentando fazer. Em primeiro lugar, eles não estão procurando clarificar as relaçôes que existem dentre os muitos diferentes sentidos nos quais a palavra "arte” é usada. Qualquer dicionário oferece uma variedade de tais sentidos (ex., a arte da navegação, a arte enquanto astúcia, arte enquanto o feito do artista etc.), e não é difícil encontrar um padrão de semelhanças de família existente dentre muitos deles. Entretanto, uma análise de tais semelhanças, e de suas diferenças, não foi, realmente, de interesse para os autores de artigos sobre os quais estamos interessados aqui. Em segundo lugar, esses autores não estavam primariamente interessados em analisar como palavras tais como "obra de arte" ou "artista" ou "arte” são ordinariamente utilizadas por aqueles que nem são estetas, tampouco críticos de arte; seus interesses estavam nos escritos os quais moldam a tradição da "teoria estética". Em terceiro lugar, devemos notar que o interesse desses autores não foi mostrar que as semelhanças de família de fato existem dentre as várias artes ou dentre as várias obras de arte; ao contrário, eles usaram a doutrina de semelhanças de família numa abordagem negativa. Desse modo, eles obviamente seguiram o próprio exemplo de Wittgenstein. A posição que eles procuraram estabelecer é que a teoria tradicional estética estava errada ao assumir que há alguma propriedade essencial ou características definidoras de obras de arte (ou algum conjunto de tais propriedades e características); como uma consequência, eles concederam que a maioria das questóes que foram feitas por aqueles engajados em escritos em estética são tipos de questóes equivocadas.

dem também realizar papéis significantes. São tais fatores que Wittgenstein negligencia em suas discussóes específicas de semelhanças de família e de jogos. 
Entretanto, tal como a discussão anterior de Wittgenstein deve ter servido para tornar claro, não se pode assumir que se há alguma característica comum a todas as obras de arte, ela deva consistir em alguma característica específica e diretamente exibida. Como as conexões biológicas dentre aqueles que estão conectados por semelhanças de família ou como as intençôes com base nas quais distinguimos entre leitura de sorte e jogos de carta, tal característica pode ser um atributo relacional, mais do que alguma característica para a qual se pode apontar diretamente e dizer: "é essa característica particular do objeto que me leva a designá-lo como uma obra de arte". Um atributo relacional do tipo requerido pode, por exemplo, apenas ser apreendido se se considerar objetos de arte específicos como tendo sido criados por alguém para alguma real ou possível audiência.

A sugestão de que a essência natural da arte é para ser encontrada em tal atributo relacional não é obviamente implausível quando nos lembramos de algumas das várias teorias tradicionais de arte. Por exemplo, arte tem sido caracterizada às vezes como sendo uma forma especial de comunicação ou de expressão ou como sendo uma forma especial de realização de desejo ou como sendo uma apresentação da verdade numa forma sensual. Tais teorias não assumem que em cada poema, pintura, peça e sonata há um ingrediente específico que os identifica como uma obra de arte; ao invés disso, aquilo que é considerado como comum a esses objetos diversos é uma relação que se assume ter existido ou se sabe ter existido, entre certas de suas características, atividades e intenções daqueles que os fizeram 36

\footnotetext{
${ }^{36}$ Eu não conheço uma passagem em que Wittgenstein põe tal possibilidade em pauta. De fato, se a passagem do "The blue book" ao qual eu já aludi puder ser referenciada como uma representante, podemos dizer que a visão de Wittgenstein das teorias estéticas tradicionais estava claramente sem fundamento. Nessa passagem ele disse: A ideia de conceito geral sendo uma propriedade comum de suas instâncias particulares se conecta com outras primitivas, muito simples, ideias da estrutura da linguagem. É comparável à ideia de que propriedades são ingredientes das coisas que têm as propriedades; por exemplo, que o belo é um ingrediente de todas as coisas bonitas como o álcool é da cerveja e vinho e daí poderíamos ter o belo puro, inalterado por qualquer coisa que é belo (p. 17). Eu falho em ser capaz de identificar qualquer teoria estética na qual tal afirmação seria verdadeira. Não seria, por exemplo, verdadeiro na doutrina de Clive Bell da "forma significante", nem seria presumivelmente verdadeiro na visão de belo de G. E. Moore, já que tanto Bell quanto Moore defendem que o belo depende da natureza específica de outras
} 
Enquanto podemos estar cientes de que é difícil encontrar algum conjunto de atributos - sendo eles relacionais ou não - o qual pode servir para caracterizar a natureza da obra de arte (e o qual não será tão vulnerável a críticas quanto muitas outras caracterizações têm sido), ${ }^{37}$ é importante notar que essas dificuldades inerentes a essa tarefa não são realmente evitadas por aqueles que apelam à noção de semelhanças de família. À medida em que se tenta elucidar como o termo "arte" é de fato usado no contexto de crítica de arte, a maioria dos mesmos problemas que surgiram na história da teoria estética vão reaparecer. Em outras palavras, análise linguística não provê uma rota de fuga dos problemas que foram de maior preocupação na estética tradicional. Esse fato pode ser ilustrado através de um exame de uma porção de um dos artigos ao qual eu já fiz alusão, o artigo de Paul Ziff intitulado "A tarefa de definição de uma obra de arte".

Para explicar como o termo "uma obra de arte" é usado e para mostrar as dificuldades que se encontram se procurarmos generalizar acerca das artes, o professor Ziff escolhe como seu ponto de partida um exemplo bem definido de uma obra de arte e se dispóe a descrevê-lo.

O trabalho que ele escolhe é uma pintura de Poussin e sua descrição ocorre como se segue:

qualidades que caracterizam isso que é a beleza. Entretanto, pode ser objetado que quando eu sugiro que o que é comum a todas as obras de arte envolve referências a "intenções", eu negligencio "a falácia intencional” (ver W. K. Wimsatt, Jr. e Monroe C. Beardsley, "The intentional fallacy”, Swwanee Review, v. 54 [1946], pp. 468-488). Esse não é o caso. A frase "a falácia intencional" originalmente se referiu a um método particular de crítica, isto é, a um método de interpretar e avaliar dadas obras de arte; não é o objetivo de Wimsatt e Beardsley distuinguir entre arte e não arte. Esses dois problemas são, eu creio, fundamentalmente diferentes em caráter. Entretanto, eu não me sinto seguro de que o professor Beardsley notou esse fato, porque, num artigo recente no qual ele se dispôs a criticar aqueles que foram influenciados pela doutrina de semelhanças de família, aparentemente se sentiu obrigado a definir arte somente em termos de características do próprio objeto (ver "The definition of the arts", Journal of Aesthetics and Art Criticism, v. 20 [196I], pp. 175-187). Se ele tivesse resistido em relacionar essa característica à atividade e intenção daqueles que fazem com que objetos tenham tal característica, sua discussão não seria, creio eu, suscetível às várias críticas levantadas contra isso pelo professor Douglas Morgan e Mary Mothersill (ibid., pp. 187-198).

37 Eu não digo "todas" essas definiçôes, porque eu acho que se pode encontrar um número de definiçôes convergentes de arte, cada qual tem mérito considerável, apesar de que cada um pode diferir ligeiramente de outros em suas ênfases. 
Suponha que apontemos à obra de Poussin "O estupro da mulher Sabina” como nosso caso disponível mais claro de uma obra de arte. Podemos descrevê-la ao dizer, primeiro, que se trata de uma pintura. Em segundo lugar, ela foi feita, e mais ainda, feita deliberada e conscientemente com óbvia habilidade e cuidado por Nicolas Poussin. Em terceiro lugar, o pintor pretendeu que ela fosse mostrada em um lugar onde pudesse ser vista e apreciada, onde pudesse ser contemplada e admirada... Em quarto lugar, a pintura é ou foi exibida numa galeria de arte onde pessoas a contemplam, a estudam, a observam, a admiram, a criticam e a discutem. O que eu gostaria de me referir aqui ao falar em contemplação, estudo e observação de uma pintura é simplesmente o que podemos fazer quando estamos interessados numa pintura dessas. Por exemplo, quando olhamos para essa pintura de Poussin, podemos focar em suas características sensuais, para a sua "olhe e sinta". Portanto, focamos no jogo de luz e cor, nas dissonâncias, contrastes, harmonias de matizes, valores e intensidades. Notamos padróes e pigmentações, texturas, decorações e adornos. Podemos também focar na estrutura, forma, composição e organização do trabalho. Portanto, procuramos por unidade assim como também por variedade, por equilíbrio e movimento. Focamos nas inter-relações formais e conexões que se cruzam na obra, na sua estrutura interior... Em quinto lugar, essa obra é uma pintura representacional com um tema definido; ela representa uma certa cena mitológica. Em sexto lugar, a pintura é uma elaborada e certamente complexa estrutura formal. Finalmente, a pintura é uma boa pintura. E isso é dizer simplesmente que a pintura de Poussin vale a pena ser contemplada, estudada e observada da maneira que eu acabei de mais ou menos descrever 38

${ }^{38}$ Op. cit., pp. 6o-6I. É um problema interessante, mas não diz respeito aos nossos presentes interesses, considerar se a pintura de Poussin deveria ser classificada enquanto uma pintura "mitológica", como o Professor Ziff a descreve, ou se ela deveria ser referenciada enquanto uma pintura histórica. 
Com referência a essa descrição devemos primeiramente notar que ela claramente não significa algo como uma completa descrição da pintura de Poussin; ela é no máximo uma descrição daqueles aspectos da pintura os quais são relevantes para que seja chamada de obra de arte. Por exemplo, nem o peso da pintura e nem seu custo de reposição é mencionado. Portanto, ou devido às suas preconcepções ou devido às nossas suposições ordinárias acerca de como o termo "obra de arte" é para ser usado, o professor Ziff foca atenção em alguns aspectos da pintura de Poussin mais do que em outros. Fazendo assim, ele está fazendo uma apelação implícita ao que é pelo menos uma mínima teoria estética, isto é, ele está supondo que nem o peso e nem o custo de reposição precisam ser mencionados quando listamos as características que nos levam a dizer de uma particular tela pintada que se trata de uma obra de arte. Em segundo lugar, devemos notar que das sete características que ele menciona, nem todas são tratadas pelo professor Ziff como sendo independentes umas das outras; nem são todas relacionadas umas às outras de formas idênticas. Será instrutivo notar algumas das diferenças dentre suas relações, uma vez que é precisamente aqui que muitos dos problemas tradicionais da teoria estética mais uma vez reaparecem.

Por exemplo, devemos notar que o professor Ziff relacionou a sétima característica da pintura de Poussin com sua quarta característica: o fato de que ela é uma boa pintura está, ele defende, relacionado às características as quais achamos que ela tem quando a contemplamos, a observamos e a estudamos. Sua bondade, entretanto, não é afirmada como sendo relacionada às suas primeira, terceira ou quinta características: em outras palavras, professor Ziff não está aparentemente afirmando que a bondade dessa obra de arte em particular depende do fato de ela ser uma pintura ao invés de ser algum outro tipo de obra de arte a qual é capaz de ser contemplada, estudada, etc.; nem ele está defendendo que sua bondade é dependente do fato de que foi pretendida para ser pendurada num lugar onde pode ser observada e estudada; nem do fato de que ela é uma pintura representacional que ilustra uma cena mitológica. Se em seguida nos voltarmos à questão de como a bondade dessa pintura é relacionada ao fato de que ela foi "feita deliberada e conscientemente, com óbvia habilidade e cuidado por Nicolas Poussin", a posição do professor Ziff é de alguma forma menos explícita, mas o que ele diria está provavelmente bastante claro. Suponha que a frase "óbvia habilidade" fosse deletada da descrição dessa característica: se essa pintura 
tivesse sido deliberada e conscientemente feita, e tivesse sido feita com cuidado (mas talvez não com habilidade), seria esse fato suficiente para prover uma base de modo a predicar bondade dela? Eu deveria duvidar de que o professor Ziff sustentaria que sim, já que pode se supor que muitas más pinturas foram feitas deliberadamente, conscientemente e com cuidado. Além disso, se for o caso, como estão relacionadas as habilidades do criador à bondade do objeto? Talvez o fato de a "óbvia habilidade" ser atribuída a Poussin queria tentar sugerir que Poussin pretendeu que "O estupro da mulher Sabina" deveria possuir aquelas qualidades as quais o professor Ziff destacou que encontraríamos nela quando a contemplamos, a estudamos e a observamos da maneira pela qual ele sugere que fosse contemplada. Se isso é o que é sugerido ao atribuir habilidade ao artista, se torna claro que o professor Ziff construiu, sem dúvida, uma teoria estética a partir de sua descrição da pintura de Poussin. Essa teoria está implícita tanto nas características que ele escolhe como sendo esteticamente relevantes como nas relaçôes que ele sustenta como presentes dentre essas características.

Se for para ser duvidado de que a descrição do professor Ziff contém pelo menos uma teoria estética implícita, considere o fato de que em uma das passagens na qual ele descreve a pintura de Poussin (mas a qual eu não incluí na minha citação encurtada daquela descrição), ele fala do fato de que ao contemplar, estudar e observar essa pintura "estamos interessados tanto nos movimentos bidimensionais como nos tridimensionais, o equilíbrio e oposição, impulso e recolhimento, de espaços e volumes". Uma vez que a bondade de uma pintura foi dita por ele como dependente de qualidades as quais encontramos nela quando a contemplamos, a estudamos e a observamos, segue-se que essas características da pintura de Poussin contribuem para sua bondade. E eu deveria supor que elas estão inclusas no que o professor Ziff chama de sexta característica da pintura de Poussin, por assim dizer, sua "estrutura complexa formal". Portanto, presumidamente, a bondade de uma pintura depende, em parte, ao menos, de sua estrutura formal. Por outro lado, o professor Ziff nunca sugere que a bondade da pintura de Poussin depende do fato de que ela é uma pintura representacional e de que possui um tema mitológico (ou histórico), ao invés de outro tipo de tema. De fato, quando ele discute críticas como as de Kenyon Cox e Royal Cortissoz, professor Ziff aparentemente - e bem apropriadamente - desejaria separar-se ele mesmo deles, rejeitando a visão de que o que faz de uma pintura uma boa 
pintura tem alguma relação necessária ao fato de que é ou não é uma pintura representacional de um certo tipo. Portanto, a abordagem do professor Ziff das características esteticamente relevantes da pintura de Poussin, e suas afirmações acerca das inter-relaçôes dentre as várias características da pintura, define uma posição estética particular.

A posição que estou atribuindo a ele é uma com a qual eu eventualmente concordo. Porém, esse fato não é de importância alguma à presente discussão. O que é importante notar é que a caracterização do professor Ziff da pintura de Poussin contém uma teoria implícita da natureza de uma obra de arte. Segundo essa teoria, a bondade de uma pintura deve depender de sua posse de certas qualidades objetivas, e que essas qualidades são (em parte, ao menos) elementos de sua estrutura formal e que o artista pretendeu que devemos perceber tais qualidades ao contemplar e estudar a pintura. (Se ele não tivesse tido essa intenção, seríamos capazes de dizer que ele fez o objeto conscientemente, deliberadamente $e$ com habilidade?). Mais adiante, essa teoria implícita deve ser assumida como uma teoria geral e não confinada a como devemos olhar a apenas essa pintura em particular. Se não fosse assim, o tipo de descrição da pintura de Poussin que foi dada pelo professor Ziff não ajudaria a estabelecer um caso bem definido do que é para ser designado como uma obra de arte. Por exemplo, se alguém tivesse que descrever a mesma pintura em termos de seu tamanho, peso e custo de reposição (como deve ser feito ao ser movida de museu para museu), nós não aprenderíamos assim como o termo "obra de arte" é para ser usado. Ao falhar em notar que sua descrição da pintura de Poussin realmente envolveu uma teoria da natureza da arte, o professor Ziff procedeu em tratar essa descrição como se ele tivesse feito nada mais que trazer à tona uma lista de sete características independentes da pintura que ele estava examinando. Fazendo assim, ele transformou a questão de se há algumas características comuns a todas as obras de arte numa questão de se um ou mais desses sete índices específicos poderiam ser encontrados em todos os objetos aos quais o termo "obra de arte" é aplicado. Inevitavelmente, sua conclusão foi negativa e ele então sustenta que "nenhuma dessas características listadas é necessariamente uma característica de uma obra de arte” 39

\footnotetext{
39 Ibid., p. 64.
} 
Entretanto, como vimos, a descrição do professor Ziff da pintura de Poussin não foi realmente confinada a notar qualidades específicas as quais são características da superfície pictórica da pintura; ela incluiu referência a relações entre essas qualidades e o objetivo de Poussin, e referência aos modos pelos quais uma pintura de tal qualidade é para ser contemplada por outros. Se ele tivesse voltado sua atenção a examinar essas relações entre objeto, artista e contemplador, teria sido certamente mais difícil para ele asserir que "nem um poema, nem um romance, nem uma composição musical pode ser dita como sendo uma obra de arte no mesmo sentido da frase na qual uma pintura, estátua ou vaso podem ser ditos como sendo uma obra de arte" $4^{+0}$ De fato, se ele tivesse cuidadosamente traçado as relações as quais ele assumiu existirem dentre algumas das características da pintura de Poussin, poderia ter descoberto que, ao contrário de suas inclinaçôes, ele foi precipitado em trazer à tona generalizações explícitas acerca das artes.

\section{III}

Enquanto o argumento do professor Ziff contra generalização depende do fato de que várias mídias artísticas são significativamente diferentes umas das outras, a possibilidade de generalização acerca das artes foi também desafiada em solos históricos. É ao uso do último argumento de Morris Weitz que eu devo me voltar.

Em "O papel da teoria em estética”, o professor Weitz pốe sua primeira ênfase no fato de que formas artísticas não são estáticas. Desse fato ele argumenta que é fútil tentar afirmar as condições que são necessárias e suficientes para um objeto ser uma obra de arte. O que ele defende é que o conceito de "arte" deve ser tratado como um conceito aberto, já que novas formas artísticas foram desenvolvidas no passado e também qualquer forma de arte (como um romance) pode sofrer

${ }^{40}$ Ibid., p. 66. Por exemplo, Ziff nega que um poema pode ser dito como sendo "exibido ou mostrado". Ainda que seja certamente o caso de que em escrever um poema ou em apresentar ou ler um poema, a relação entre a obra e sua audiência, e a relação entre artista, obra e audiência, não é totalmente dissimilar àquilo que se obtém quando um artista exibe uma pintura. Se duvidarmos disso, considere se não há uma afinidade mais íntima entre esses dois casos do que há entre um pintor exibindo uma pintura e uma fábrica exibindo uma nova linha de canetas tinteiro. 
transformações radicais de geração em geração. Uma breve afirmação do artigo do professor Weitz pode servir para resumir essa visão:

O que eu estou discutindo, então, é que o próprio expansivo e aventuroso caráter da arte, suas sempre presentes mudanças e inovações, torna logicamente impossível assegurar algum conjunto de propriedades definidoras. Podemos, claro, escolher fechar o conceito. Mas fazer isso com "arte", "tragédia" ou molduragem etc. é ridículo, uma vez que isso limita as próprias condiçốes de criatividade nas artes $4^{41}$

Infelizmente, o professor Weitz falha em oferecer algum argumento convincente em comprovação de sua afirmação. A lacuna em sua discussão pode ser encontrada no fato de que a questão de se um conceito particular é aberto ou fechado (isto é, se um conjunto de condições necessárias e suficientes pode ser oferecido para o seu uso) não é idêntica à questão de se instanciaçôes futuras às quais o próprio conceito é aplicado pode ou não pode possuir genuinamente propriedades inéditas. Em outras palavras, professor Weitz não mostrou que toda inovação nas instâncias às quais aplicamos um termo envolve um estiramento da conotação do termo.

A título de ilustração, considere o rótulo classificatório "pintura representacional”. Pode-se certamente definir essa forma particular de arte sem defini-la de uma tal maneira em que irá incluir apenas aquelas pinturas que representam tanto um evento mitológico ou uma cena religiosa. Pinturas históricas, de interiores, fête-champêtre ${ }^{42}$ e natureza-morta podem todas contar como "representacional" de acordo com qualquer definição adequada desse modo de pintura e não há razão alguma do porquê tal definição poderia não ter sido formulada anteriormente à emergência de alguma dessas espécies inéditas do modo representacional. Portanto, definir uma forma particular de arte - e defini-la verdadeira e preci-

${ }^{41}$ Op. cit., p. 32.

${ }^{42}$ Trata-se de uma representação um evento festivo em céu aberto onde indivíduos da alta aristocracia, bem-vestidos e relaxados, gozam de seus privilégios num cenário rural ou pastoral. (N. da T.) 
samente - não é necessariamente definir a si próprio em oposição a quaisquer novas criaçôes que podem surgir interiormente àquela forma particular ${ }^{43}$

Consequentemente, seria errado supor que todas as tentativas de afirmar as propriedades definidoras de várias formas de arte são prescritivas em caráter e autoritárias em seus efeitos.

Essa conclusão não está confinada a casos em que uma forma de arte estabelecida, como uma pintura representacional, sofre mudanças; pode-se também mostrar que ela é compatível com o fato de que formas de arte radicalmente novas surgem. Por exemplo, se o conceito "uma obra de arte" tivesse sido cuidadosamente definido anteriormente à invenção de câmeras, há alguma razão para supor que tal definição proveria um obstáculo à visão de fotografia ou de filmes enquanto constituintes de novas formas de arte? Para ter certeza, pode-se imaginar definições que podem ter passado por isso. Todavia, não foi o objetivo do professor Weitz mostrar que uma ou outra definição de arte tinha sido uma definição pobre. Ele queria estabelecer a tese geral de que há uma incompatibilidade necessária, a qual ele denotou como uma impossibilidade lógica, entre permitir a inovação e criatividade nas artes e afirmar as propriedades definitórias de uma obra de arte. Ele falhou em defender essa tese já que ele não ofereceu argumento algum para provar que novos tipos de instanciaçôes de um conceito previamente definido irão necessariamente nos envolver ao mudar a definição do conceito.

Para ter certeza, se nem fotografia e nem filmes tivessem se desenvolvido ao longo de linhas que satisfazem os mesmos tipos de interesse que outras artes satisfazem, e se os tipos de padrões que foram aplicados em outras artes não fossem vistos como relevantes quando aplicados à fotografia e nos filmes, então

43 Para ter certeza, se nenhuma característica de continuidade puder ser encontrada, o fato de mudança irá exigir que o conceito seja tratado como sendo um aberto. Esse foi precisamente a posição tomada por Max Black numa discussão do conceito "ciência". (Ver "The Definition of Scientific Method”, em Science and Civilization, editado por Robert C. Stauffer [Madison, Wisconsin, 1949]). Paul Ziff se refere à influência da discussão da visão do professor Black sobre suas próprias visões e as visões de Morris Weitz são certamente similares. Porém, mesmo se a visão do professor Black das mudanças no conceito de "ciência" estiver correta (como eu deveria estar preparado a pensar que possa estar), não se segue que o mesmo argumento se aplica no caso da arte. Nem o fato de que o significado de "ciência" sofreu profundas mudanças no passado implica que futuras mudanças análogas ocorrerão. 
a definição de arte antecedentemente formulada teria funcionado como um conceito fechado e teria sido usado para excluir todos os fotógrafos e criadores de cinema da classe daqueles que eram para ser classificados como "artistas". Porém, o que o defensor da abertura de conceitos sustentaria que se deveria ter feito nessas circunstâncias? Suponha, por exemplo, que todos os fotógrafos tivessem sido de fato equivalentes a fotógrafos de passaporte e que eles tivessem sido motivados por nenhum outro interesse e controlados por nenhum outro padrão além daqueles que governam o tirar fotos para passaportes e licenças: o defensor de conceitos abertos provavelmente teria expandido o conceito do que é para contar como uma arte de modo a ter incluído fotografia? A presente inclusão de fotografia dentre as artes é justificada, eu deveria sustentar, precisamente porque fotografias surgem dos mesmos tipos de interesse, e podem satisfazer os mesmos tipos de interesse, e nossa crítica disso aplica os mesmos tipos de padróes, como no caso que diz respeito a outras artes.

Com isso em mente, estamos em posição de ver que ainda outro artigo que foi citado por aqueles que argumentam a favor da abertura do conceito "uma obra de arte" não justifica as conclusões que foram retiradas daí. Esse artigo é o culto e informativo estudo de Paul Oscar Kristeller "O moderno sistema das artes" ${ }^{44}$ A maneira com a qual o professor Kristeller mostra o objetivo de seu artigo sugere que ele também negaria que a teoria estética tradicional é capaz de formular generalizações adequadas acerca das artes. Ele mostra seu objetivo ao dizer:

A noção básica de que as cinco "grandes artes" constituem toda uma área por elas mesmas, claramente separada por características comuns das criações, ciências e outras atividades humanas foi deixada de lado pela maioria dos autores em estética desde Kant aos dias presentes...

É meu propósito mostrar que o sistema das cinco grandes artes, o qual fundamenta toda a estética moderna e é tão familiar a todos nós,

${ }^{44}$ Journal of the History of Ideas, v. I2 (1951), pp. 496-527, e v. 13 (1952), pp. 17-46. Esse estudo foi citado tanto por Elton (op. cit., p. 2) como por Kennick (op. cit., p. 320) na comprovação de suas visões. 
é de origem comparativamente recente e não assumiu forma definida antes do décimo oitavo século, ainda que tivesse muitos ingredientes que voltam ao pensamento clássico, medieval e renascentista. 45

Entretanto, o fato de que a classificação das artes indubitavelmente mudou durante a história do pensamento ocidental, isso por si mesmo não sugere que a teoria estética deva sofrer mudanças comparáveis. Se tivermos que duvidar disso, pode-se notar que o artigo do Professor Kristeller não mostra de quais modos específicos tenta classificar ou sistematizar as artes como integrantes à, ou pressupostas por, ou que são consequências da formulação de uma teoria estética. Isso não é apenas implicância, porque se examinarmos os autores em estética que são atualmente atacados por suas tentativas de generalizar acerca da natureza da arte, notamos que eles não são (de modo geral) autores cujas discussões estão intimamente aliadas às discussóes daqueles com quem o artigo de Kristeller estava primariamente preocupado. Além disso, é para ser notado que Kristeller não levou sua discussão além de Kant. Esse ponto terminal foi justificado por ele com base no fato de que o sistema das artes não mudou substancialmente desde o tempo de Kant ${ }^{46}$ Porém, quando nos lembramos de que o trabalho de Kant é geralmente referido como estando perto do início da teoria estética moderna - e certamente não perto de seu fim - temos razôes para suspeitar que questóes acerca "do sistema das artes" e questóes acerca da teoria estética constituem conjuntos de questôes distintos e provavelmente separados. Uma pesquisa da recente teoria estética revela isso. Desde o tempo de Hegel e Schopenhauer houve comparativamente poucas teorias estéticas influentes as quais fizeram do problema da diversidade das formas artísticas, e a classificação dessas formas, central às suas consideraçôes da natureza da arte ${ }^{47}$ Por exemplo, as teorias estéticas de Santayana,

${ }^{45}$ Op. cit., v. 12, p. 497.

${ }^{46}$ Op. cit., v. I3, p. 43; também, pp. 4 ff.

47 Uma exceção pode ser encontrada em T.M. Greene: The arts and the art criticism (Princeton, 1940). Esse trabalho é citado por Kristeller e é um dos únicos dois que ele cita em suporte da visão de que o sistema das artes não mudou desde o tempo de Kant (op. cit., v. I2, p 497, n. 4). O outro trabalho citado por ele é o System der Kunstwissenschaft (Brünn/Leipzig, 1938), que também oferece uma classificação das artes, mas apenas dentro uma estrutura da teoria estética a qual poderia facilmente embarcar qualquer mudança histórica que as artes possam sofrer. 
Croce, Alexander, Dewey, Prall ou Collingwood não podem ser ditas como tendo sido dependentes de qualquer classificação sistemática particular das artes. Na medida em que essas teorias podem ser vistas como representantes das tentativas de generalizar acerca das artes, é estranho como os presentes ataques à estética tradicional deveriam ter suposto que qualquer atitude especial de apoio era para ser derivada do artigo de Kristeller.

Se pudéssemos entender por que as discussóes recentes negligenciaram o vazio entre um artigo como o de Kristeller e as lições ostensivamente derivadas disso, uma explicação poderia ser encontrada na falta de preocupação evidenciada por filósofos analíticos contemporâneos para os problemas da teoria estética tradicional. Por exemplo, procuramos em vão no volume de Elton por uma avaliação das relaçôes entre a teoria estética e a crítica de arte e como as funções de cada um podem se diferenciar das funções da outra. Um exemplo devastador dessa falha em considerar esse tipo de problema é também encontrado na citação frequentemente citada de John Wisdom acerca da "estupidez" da teoria estética. $4^{48}$ Ao examinar suas visóes encontramos que os livros sobre arte os quais Wisdom não acha estúpido são livros como o Castelo de Axel de Edmund Wilson, no qual uma crítica "traz à tona características da arte sobre a qual ele escreve, ou melhor, traz de volta o caráter daquilo sobre o que ele escreve", 49 Em suma, não é teoria - não é de maneira alguma teoria estética - que o Wisdom está procurando: acontece que ele está interessado em crítica.

Eu não quero ser visto como negando a importância da crítica, nem como menosprezando a contribuição que uma abordagem completa com a prática da crítica em todas as artes pode fazer à teoria estética geral. Todavia, é importante notar que o trabalho de qualquer crítica pressupóe pelo menos uma teoria estética implícita, a qual - enquanto crítica - não é seu objetivo estabelecer ou, em geral, defender. O fato só pode ser negligenciado por aqueles que confinam a si mesmos num estreito espaço de crítica: por exemplo, para a crítica aparecendo em nosso próprio tempo naqueles artigos que são lidos por aqueles com os quais temos afinidades intelectuais, políticas e sociais. Quando não nos confinamos desse jeito,

${ }^{48}$ Ver "Things and persons", Proceedings of the aristotelian society (Sumpplementary), v. XXII (1948), pp. 207-210.

49 Ibid., p. 209. 
rapidamente descobrimos que há, e houve, uma enorme variedade na crítica e essa variedade representa (em parte ao menos) o efeito de diferenciar preconcepçóes estéticas. Para avaliar a crítica em si nós devemos, então, às vezes nos dispor a avaliar essas preconcepçôes. Em suma, devemos nós mesmos ser estetas.

Entretanto, para muitas das críticas da estética tradicional isso é uma opção que não apela. Se eu não estou errado, não é difícil ver por que isso deveria vir a ser assim. Em primeiro lugar, veio a ser uma das marcas da filosofia analítica contemporânea sustentar que problemas filosóficos são problemas que não podem ser resolvidos ao apelar a questôes de fato. Portanto, escolher apenas uma posição, questôes de relações entre a percepção estética e outras posiçóes de percepção por exemplo, questóes acerca da distância psíquica, ou percepção empática, ou o papel da forma na percepção estética - não são consideradas questôes as quais um filósofo deveria tentar resolver. Em segundo lugar, a tarefa do filósofo veio a ser vista como consistindo amplamente em resolver emaranhados nos quais outros se perderam. Como uma consequência, a tentativa de encontrar uma interpretação sinótica de uma larga gama de fatos - uma tentativa que no passado foi considerada como uma das grandes tarefas de um filósofo - foi também aviltada ou totalmente negligenciada 50 Portanto, problemas como as afirmações das artes para formar uma abordagem verdadeira do destino e do caráter humano ou questôes acerca das relaçóes entre a bondade estética e padrôes de grandiosidade em arte ou uma estima da significância da variabilidade dos julgamentos estéticos não estão populares no momento. E deve ser admitido que se filósofos não desejam ter que encarar tanto os problemas reais como as tarefas sinóticas, essas são realmente questôes que são mais confortavelmente evitadas que procuradas.

so Por exemplo, a obra "The function of philosophical aesthetics" de W. B. Gallie, no volume de Elton, argumenta a favor de "uma estética contratada”, a qual lidará com problemas individuais, um por um, sendo esses problemas do tipo que surgem quando um crítico ou poeta entra na confusão sobre termos como "abstração" ou "imaginação". Para esse propósito as ferramentas do filósofo são tomadas como sendo ferramentas de análise lógica (op. cit., p. 35); um interesse na história das artes, na psicologia ou numa direta e ampla experiência das artes não parece ser pressuposta. Um segundo exemplo das limitações impostas em estética pela análise linguística contemporânea pode ser encontrado no artigo do professor Weitz. Ele afirma que "o problema raiz da própria filosofia é explicar a relação entre o emprego de certos tipos de conceitos e de condições sob as quais eles são corretamente aplicados” (op. cit., p. 30). 